\title{
Words of Wisdom in the EFL P.F.C.E. Corpus
}

\author{
Liliana Landolfi \\ Università degli Studi di Napoli, “L’Orientale”, Italy
}

\begin{abstract}
The paper focuses on today's foreign language learning (FLL) as seen by first-year language students at university. It investigates, through the analysis of students' written self-representations, aspects of their FLL belief system and the impact that these aspects have on their pedagogical evolution.

The data under observation come from the EFL P.A.C.E. Corpus, which gives voice to more than 500 students of English who self-described their learning states at the beginning of their first-year course and after a visualization that was implemented using NeuroLinguistic Programming (NLP) modalities.

In itinere qualitative analyses have so far: 1) shown that many students come to university with a clear vision of who they want to be but with a number of blocking factors; 2) allowed unobtrusive observations about their emotional states, and 3) highlighted aspects of affective teaching needing implementation in foreign language (FL) teacher-training courses.
\end{abstract}

\section{Introduction}

An analysis of foreign language teaching (FLT) approaches from the fifties to the present educational scenario offers a clear idea of how significant a transformation language teachers have undergone [17]. The transformational process has affected the field of education [12] involving both teachers and students [21]. It derived from a gradual shift in focus from teacher-based to student-geared pedagogy embedded within a gradually more relevant technology-oriented frame. Its roots can be traced in the developments that took place in many language-related areas (e.g., secondlanguage acquisition (SLA) theories, applied linguistics, computer-assisted language learning [CALL], sociolinguistics, psycholinguistics), as well as in teaching management and daily classroom praxes deriving from students' needs analyses. Indeed, these gradually deeper language learning (LL) investigations, based on observations at all levels of language teaching/learning (e.g., children vs. adult education, private vs. public contexts, large vs. small classes), permeated the literature on the topic and caused changes, innovations, and rearrangements to occur in teaching programs, strategies, and settings.

All the same, still more needs to be known about our students' needs, particularly with reference to the affective aspects [2] of FLL. Although in the past students have rarely been given the opportunity to express their opinions and beliefs about their learning paths, recent tools $[13,24]$ allow them to do so and allow researchers to deepen investigations on LL. Selfawareness about language matters, as well as selfassessment and self-evaluation of one's personal language proficiency level can all be achieved. Students are becoming more and more responsible for their language development. The question is, once students have expressed their visions about language acquisition, are we, as educators, capable of acting accordingly and favoring them? Are we aware that the leaders of tomorrow, in our multilingual and multifaceted world, need modern learning visions that will help them act, inter-act, and re-act linguistically at a high level of competence?

To touch upon these contemporary issues, it might be worth looking at their origins through a brief historical excursus on needs analysis [37] in formal LL contexts.

\section{Students' needs analysis in perspective}

With the Council of Europe [1] and the beginning of the notional-functional era [41], students' needs have been taken into consideration [30] mainly for FLL and SLL (second language earning) syllabi and curriculum design [27]. Differences between FLL and SLL are not highlighted here, though distinctions exist [23].

Needs-related lists and typologies filled the literature of the time; I contributed to that flow. Nowadays, however, looking back, I realize my vision of what language students needed, as co-shared by other applied linguists, reflected a perspective which was time bound 
and teacher dependent. How could we have proceeded differently, though? As language educators, we were all coming from an education in language teaching which had its roots in the Grammar Translation Method [32], had survived through the Audio-Lingual Method [29], developed via the Situational Approaches [28], and seen the light within the Affective Methodology [36] in the USA and the Notional-Functional Approaches in Europe [5]. We could only welcome the innovative, communicative focus on students and on their needs [13].

At the time, the analysis of students' needs was functionality geared and teacher derived [26]. The psychological and affective sides of LL were minimally relevant in the scenario. The focus was mainly on aspects related to the well-being and well-functioning of FL courses. Teachers primarily looked at:

- learners' age (children, teenagers, adults),

- students’ proficiency levels (pre/upper elementary, intermediate, advanced)

- course length (from short and intensive to gradual and elongated across years),

- approach selection (from situational methods to notional-functional or affective approaches, mainly in the USA [31]),

- skill focus (receptive and/or productive),

- content segmentation (selection and gradation), and

- testing and evaluation (test typologies, subjective and/or objective parameters, overt/covert frames).

Investigators devoted very little attention to the affective side of language learning, although they began to analyze language attitude and aptitude [40] within an affective-oriented framework [25, 35]. In spite of these advances, however, at a deeper level, language-related issues, though focusing on students, were still embedded in the teachers' hands within the scholastic environment.

In the 80s, students were just starting to travel across the world with educational exchange programs. They barely understood they were responsible [34] for their own learning and were expected to become autonomous [11] in LL. The Internet was available for educational investigations mainly at campuses; personal computers were still very expensive. In the early eighties LL essentially took place in class or in the language laboratory [33]. Lucky were those students who could travel internationally or live with native speakers of the target language (TL) particularly if these (e.g., bilingual families, international friends, au-pairs) were directly or indirectly willing to practice it with them in social interactions and/or through friendly exchanges where language-bound explanations could take place.

Around the nineties, when the students started to have a voice in the language scenario and express comments and opinions on language matters [38], the focus on their learning needs became more precise (students could express their visions about language learning environments), but still teacher-controlled. Ten more years had to pass before a diverse type of studentbased tool could become operational, the European Language Portfolio (ELP), and for students to be allowed to investigate language matters on their own.

\section{Awareness builders}

The ELP was created within the Common European Framework (CEFR) of Reference for Languages [6]. It still is an innovative tool, less keen on curriculum development and more directed to each student's needs assessment, LL history, and proficiency expansion. ELP's pedagogic function lies in putting learners in the condition to observe and evaluate their own proficiency level, acknowledging the personal efforts that were necessary to reach a specific level (from A1 to C2) in the CEFR scale [7], and being aware of what still needs to be accomplished to get to the next level. ELP offers learners a more transparent modality to look at their personal LL process and educators a more objective language teaching (LT) scenario.

Though numerous versions of ELPs appeared in various European countries and languages, they all shared (and still do) common ideas and were articulated in three sections [24]: 1. Language passport, 2. Language biography, and 3. Dossier. Relevant among these is the language passport (LP) because, besides listing the languages the student has competence in and showing his/her current level of proficiency, it functions as an awareness builder. It contains a series of forms and worksheets [10] to fill in so as to self-assess the level of language acquisition temporarily reached. Through its correct use, students identify the areas (e.g., pronunciation, grammar, vocabulary, speaking, reading comprehension, composition) they need to work on.

Self-assessment [3] makes learners more attentive to their personal needs in language proficiency development. They gradually become capable of autonomously recording [22] their own learning path and identifying language areas needing improvement. Students establish independence from their teachers, nurture LL responsibility, and become accountable for what they learn and how they approach their learning path. Little by little, students build their visions (mental schemas) related to who they want to become as language learners and what they want to achieve, understand the steps that were made to reach a specific proficiency level, and identify the ones that must be mastered to go beyond it. In so doing, they should become aware of the personal beliefs and mental blocks that obstruct their learning path (see sections to come). 
The support that ELPs offer is crucial for building LL awareness but less valid for identifying and unblocking affective barriers, as we shall see shortly. A different tool is necessary for that and guided visualizations (GVs) are a possible useful tool for building emotional awareness. Before discussing them in some detail (see section 6.), however, it is important to stress the importance of not considering students as dehumanized learning devices (as expressed by a couple of teachers during a recent training course), just needing a fixed number of hours of language study and practice $[6,7]$ and some self-assessment forms to move through the various CEFR levels. Such an attitude fails to appropriately consider and value the pushing force that positive affect-geared mind frames play in LL. Indeed, these can activate desire and determination (as examples in section 8. show), can support faster developments in LL empowerment, and make students go beyond the traditionally ascribable time-bound learning frame. A closer look at EFL learners might be of help.

\section{EFL contemporary learners}

Contemporary FL students, particularly if adults and at university, may take advantage of more than the selfassessment and awareness-building devices above described (ELP, GV). They have choices that prior student generations did not have, to the point that they may not even need a classroom context to embed and cocoon their learning process in. They may access a number of education-oriented language facilities (e.g., eduware, online libraries, grammar checks, free TV educational programs, websites, e-mail, blogs) in the comfort of their own homes or in the hundreds of nocost self-access areas scattered worldwide (mainly at university campuses). They have online tools to practice, test themselves and establish their own desired level of proficiency. Being corrected, explained, and tutored can all take place independently from sitting in the language class with a teacher.

With all these LL facilities, FL learners could well be expected to show an independent, fast, and proficient FLL attitude and dash through language programs without problems and at the right pace. Unfortunately, this is not always and not necessarily the case. More often than supposed, final results are not as satisfactory as both language learners and teachers expect them to be. The number of students who enroll in language faculties and then leave college is significant as is the number of "fuoricorso" students (those who do not complete the credits they are supposed to in the timeframe the university system defines) who continue being enrolled though not in alignment with mainstream students. Often, students have completed all requirements for their degree except for the foreignlanguage courses that, having dragged on for years, create in the students frustration, nurture a sense of incapacity with consequent detachment from the TL, and, in many cases, from graduation. Something must be blocking these students' learning visions or be missing from the FLT approach in use.

In order to identify some of the aspects that create conflict and slow down harmonic LL development, I carried out a longitudinal study at the University of Naples “L'Orientale” with the auspices and sponsorship of the Faculty of Foreign Languages and Literatures. The research project used GVs as tools for deconstructing negative learning schemas (see examples in 7.) and triggering new positive ones (see examples in 8.). The project concretized in the creation of a bilingual corpus (see below) that, after a number of prior versions, is now available for investigations in its final electronic format.

\section{The EFL P.E.C.E. Corpus}

The EFL P.Æ.C.E. Corpus [18] is a collection of authentic class-driven texts where students are given the opportunity to express, in a written format, their innerrepresentation and self-interpretation of who they think they are as students of foreign languages and who they would like to be. This inner look into students' perspectives about their world as language learners makes the EFL P.Æ.C.E. Corpus a rather unusual collection of texts where students themselves give voice to their learning process, fatigue, needs, and more or less disciplined efforts to reach what some of the students named a "dream competence," in a language (English) that may make a difference in their future lives and in the occupational world of tomorrow.

Students are not frequently given the opportunity to express freely what they think about their learning path and about their choices as learners. This is particularly true in academic teaching environments, and with large classes (like in Italian public universities where, depending on the subjects, it is not rare that even more than 150 students are present in class per lesson). Too many intervening factors (time limitations, program completion, educational barriers, classroom arrangements, misconceptions about identity-driven investigations, colleagues' potential misinterpretations, maintenance of teachers' institutionalized roles, etc.) may come into play and make analyses of this type difficult, time consuming, and initially unrewarding for goal achievements and career development. Monitoring inner aspects of self-representation and identity awareness necessarily leads to deal with human variables such as: ego factors, colorful interpretations of 
reality, arrays of (dis)comfort with the pedagogical system, just to name a few, and all of these push to relegate investigations of this type into the realm of TOO: "too difficult, too embarrassing, too wide," or simply "too poorly relevant for teaching objectives."

Nevertheless, despite difficulties, embarrassment, and constraints, even simple and costless investigations of this type, as the examples will show, may prove to be relevant for methodologists, teacher-training planners, future teachers, students themselves, and those who are interested in foreign/second language learning. When compared to other internationally known corpora, the EFL P.Æ.C.E. Corpus, though slightly larger than 100.000 words, results being rather small. Its peculiarity relies on the fact that, besides allowing to explore the traditionally-geared linguistic analyses in an unobtrusive way, it also favors investigations on the set of beliefs, expectations, hopes, certainties, dreams, and their linked emotions, that students carry with them when first approaching academic studies. Further, due to its diachronic nature, it also allows to observe changes in the students' voices, thus indirectly opening a window on the temporary or ever-showing demands and on-going burdens which slow down, put on hold, or even block the process of second-language acquisition.

The protocol [20] foresaw three phases: Opening declaration, Guided visualization, and Introspection. More than 500 students volunteered to offer, in anonymous texts, self-representations of their learning states (Phase I) at the beginning of their first-year course of English Language and Linguistics I. They talked about their inner worlds, their positive and negative attitudes and affective actions or reactions toward the TL, before and after a visualization (Phase III). Students were required to report about their mental journey (as they called it) describing the experiences the GV had stimulated, giving as many details as they could in the allotted time (7-8 minutes). As already stated, the visualization (Phase II) was orchestrated following NLP modalities since emotional awareness is better achieved through the activation of all the five senses..

\section{NLP guided visualizations}

NLP studies [9, 14] suggest that affective mental blocks cause the creation, and cerebral fixing, of behavioural schema limiting and/or negatively influencing learning environments. However, when these mental blocks are appropriately neutralized, using the correct procedure, individuals may be freed from their limits in whatever field of occurrence the limiting behaviour becomes manifest. Indeed, NLP applications are oriented toward the elimination of those mental blocks [2] that inhibit personal growth [35].
NLP adopts tools and techniques coming from a variety of scientific fields (e.g., linguistics, psychology, cybernetics, quantum linguistics). Among them, visualizations were selected for their flexibility and easiness of use. The term visualization has assumed a variety of meanings over time, according to the fields of use. Some relate to psychology and mental hypnotic therapy, such as the term "induction"; others are more inventive, like “daydreaming”, “mental image”, "guided meditation", "mental representation", and so on. The students in the corpus have referred to it using the terms "mental dream", "fantasy trip", and "mind travel", among others; and, as their written productions report, they have enjoyed the event greatly.

After all, visualizations have always been an integral part of what it means to be human. Beside the fact that we all use images to memorize facts, events, and realities, we are all skilled in daydreaming trips and imaging routines. Indeed, nobody can deny imagining events, situations, happenings where details are planned, sensations experienced, words uttered in one's own mind, a virtual and unreal environment. Nonetheless, the visualized event is felt as real and the anchored sensations, investing all of the five senses, whether beautiful or disgusting, are forcefully experienced $[14,16]$.

GVs are moderately new in the field of FLT [2], but they are successfully and widely used in other goalachievement and personal-development areas (e.g., coaching, other/self management, leadership, sports). As learning activators, visualizations $[14,16]$ may function not only as emotional awareness builders but also as motivation busters and self-esteem pushers. Recent investigations [18, 19], carried out on university students' belief systems (e.g., what students prefer, are sure of, expect) and mental spheres (e.g., aspects connected to anxiety, fears, doubts, forms of resistance, incredulity, shyness, mindframes), indicate that how the students view themselves impinges significantly on the affective side of FLL, plays a relevant role, and felicitously contributes to LL (see 2_07_08_EN in section 8.).

When visualization are not self-directed but guided by someone else, their force increases drastically. The guiding voice frees the listener from planning the plot of any story, and the listener's mind can safely abandon itself to the flow of images. They rapidly come and go, following the guiding voice, in a phantasmagorical sequence which has sense, value, and meanings just and only for the person who is directing the scenes, the visualizer and his/her own movie. The guided aspect provides a well-designed structure for the mental representations that gradually take place, while allowing the guide to maintain a sort of distant control, so that all the members in the audience can follow the same path, 
and colour it with their own images, experiences, and emotions.

During GVs, the left hemisphere of the listener's brain can abandon the constant control required by the rational world we live in. As a result, the right hemisphere may become temporarily prevalent. The imaginative, artistic, and creative side that is in each of us can become fully active without being bound by time or space limits but rather be freed to the point of dealing with the past and the future as being both present in the on-going actions happening in the mental region. As children, we have all grown up practicing the art of imagining events, facts, happenings. Fantasizing has helped us to understand the rules and norms of the various societal roles around us. They have created and sustained attitudes and behaviours that, with time going by, have institutionalized and formed who we are in the present. Unfortunately, becoming adults, many of us have lost this positive capacity. This has led many to be anchored within routinized behaviours where mind surpasses heart and leaves small room to emotions.

The data in the next two sections, however, illustrate that, if appropriately used, mental images can greatly sustain learning, reinforce memorization, and uphold attention. Indeed, even in those cases where selfrepresentations and self-images project internal scenarios that may relegate students in a discomfort learning zone (section 7.), GVs may still be of help (see section 8.).

\section{Self-representations and self-images}

In section 5., the project protocol was briefly sketched in its three major phases. The two texts that the students produced during phase I (opening declaration) and phase III (introspection) functioned as unobtrusive mirrors of the participants' internal language-sensitive past histories and self-images. They allowed me to sketch a prototypical image (the way students see themselves as learners of English) of incoming language learners. The implicit value of this analysis, as expressed by the students themselves, was the expanded awareness students gained about LL personal needs and possibilities. The explicit value for many of them was a visible empowerment (see example 2_07_08_EN) of personal motivation [15], the establishment and/or nurturing of a "YES, I CAN" mental framework [17], and a sense of freedom and independence pushing toward self-made success.

In particular, the texts written before the visualization functioned as mirrors of the students' past experiences with English. Students offered information about prior types and lengths of English courses, as well as about their interactions with previous teachers, their pre-enrolling attitudes, and their feelings toward the TL.

Consider the examples below. All the texts (as the ones that follow) come from the above mentioned corpus. They have neither been textually modified nor linguistically polished. They appear as they were voluntarily and anonymously produced by the corpus actors. Reference codes are given at the top of the examples, deleted segments are indicated via square brackets [...], and students' cancellations are indicated by the sequence " $\approx x x "$.

\section{1_08_07_EN}

I have $\mathrm{xxx}$-studied this language at school. My teacher was not so good ... I'm not so good. I speak bad English, the first language in the world and I am bad in english. xxx-not funny! Is important for me to speak $\mathrm{xxx}$ xxx-with other people. I like very much the countries different where english is born. English is important for go and leave Italy. I know communication is important I want to learn more, my mother too wants I speak english well.

1_07_14_EN

I had many doubts in the choise of my university studies [...] Naturally I love studying foreign languages, above all English [...] but I'm not sure of my actions, of my abilities and many times I'm afraid of comparison with people. I always try to be perfect in every singol case, but I can't. [...]

\section{1_07_112_un_47_EN}

I am here because I want work abroad. I hope it will be possible. I am afraid because I hope that possible but I am not sure so I will try to $\ldots x x$ study english in a perfect way.

I choose "Orientale University" because I know that is the best place to study languages so if languages are my passion I am sure that "Orientale” will be my place. [...]

As the example show, students wrote about their high or low expectations, self- or other-sustained motivation, desires, fears, and various other aspects allowing a screening of the their set of beliefs, language desiderata, and presuppositions. These selfrepresentations and self-images made their enrollment choice transparent, described who they think they were as FL learners, who they would like to be, and how they would like to achieve their goals. They also made it possible to advance some hypotheses about the impact that these aspects would have on their emotional worlds, limiting or enhancing their pedagogical evolution in the TL.

From the in-itinere analysis of the data, it emerges that most students know about the CEFR system and, though no direct reference is made to ELPs, proficiency awareness and competence self-assessment belong to their schooling scenario (as it emerges from their texts). All of them understand the importance of becoming 
fluent in English (e.g., to get a job in Italy or abroad, to travel, to enjoy international interactions, to understand and have one's own music understood globally, to become a language teacher). But they approach its study with a variety of potentially diminishing factors and conflict-activating mindframes. These impinge negatively on getting high marks in coursework and completing required credits on time. Major among these blocking factors are:

Flickering motivation types: In the majority of the cases, students manifest a motivation that is instrumental in nature with some integrative picks. It is passion boosted though poorly achieved. In several cases, it is family activated rather than selfsustained; in some case it appears to be purely accidental;

Poor self-esteem: Many students openly state they have problems with self-esteem due to negative relationships with previous English teachers, poor results, class-driven infelicitous attitudes, errorrooted embarrassment, experiences that caused the students to lose face, or simply a paralyzing shyness that keeps them from actively participating in class;

Poor study skills: Though students arrive at university after a minimum of thirteen years of schooling and more or less the same amount of years of exposure to English teaching/learning (generally three weekly hours per nine months in a row), often they have not yet acquired efficient study skills. They are still teacher dependent and rarely autonomous in learning. This shines through the many direct or indirect requests that are expressed in the texts and that ask the teacher to be indulgent, patient, and available;

Many and diversified types of fears: Students report a series of major fears about both oral and written exams, speaking in public, attending a large class (often more than 150 students), being unable to live up to unrealistic expectations of their families or themselves, facing a new learning approach and a new study setting, activating functional studentteacher and student-student relationships, coping with many and diversified educators, lacking enough time to study, having chosen the wrong faculty, dreading the likelihood of abandoning college, staying parked at university without good job prospects, and more;

Inaccurate awareness of personal proficiency: This aspect is closely linked to the two that follow. The university acceptance system invites students of English to enroll with a B1 competence level, but no strict admission tests are carried out and essentially all students may join the first-year course of English Language and Linguistics. This gives the students an erroneously optimistic view of their personal competence in the TL and/or an imprecise recognition of areas in linguistics where their foundation is shaky (e.g., poor syntax, poor sentence construction, minimal paragraph development). A reading of the extracts from the EFL P.Æ.C.E. Corpus will clearly substantiate this point [18]. Indeed, since the corpus contains authentic, unpolished texts, it can also be used to observe and evaluate the proficiency entry-level students show in writing at the beginning of their first academic course in the TL but after a minimum of eight years (in several cases up to thirteen) of formal LL exposure in the school system prior to university enrollment;

Inefficacious timeframes: A significant number of students look at their first college English course as a sort of magic venue where they can learn "all English" (as students write in their texts) that is needed, in order to remediate prior deficiencies in the TL (generally around pronunciation and grammar). Though pushing oneself to improve one's own problematic LL areas is the right approach, accomplishing such a major reset by the end of a fifty-hour course at university is unrealistic and leads to the next blocking aspect:

High and unreachable expectations: Many students expect to "know all English" and become both fluent and accurate in the TL by the end of the course without being aware that they arrived at university with a competence level below the university requirement (B1 on the CEFR scale) and brought with them one or more of the blocking LL factors listed above. Such students set for themselves goals that are virtually unattainable in one semester. Their unfulfilled expectations in turn nurture frustration and detachment from the TL.

The list above shows aspects of students' belief system when they first enter university. It is not difficult to realize that these beliefs work as language entanglements, guarantee failure, and keep students stuck at university for extra years.

Besides these conflicting self-representations, however, the data in the corpus also show that students want to be active constructors of their future worlds, desire to become proficient in English, wish to integrate and fulfill their goals, and dream about getting a good job, possibly abroad. In the students' visions about their future lives, English countries, English cultures, English people, all the Englishes around the world, and English music are present as a magnetic and pulling force. Educators need to strengthen these visions so they can trigger achievement. 


\section{Students' voices}

It goes without saying that old schemas and fears about LL need to be revised and/or replaced with novel visions that support students' self-confidence and contribute to achieving their realistic goals about mastering English. In a fast moving world, such as the one we live in, where images populate our imagination, nurture our dreams, and lead us to believe we can make those dreams come true, the Corpus texts indicate the students are willing to live through a virtual vision about the TL. A vision that would allow them, in their mental space, to direct the mental journey and create their own revised visions about future life realizations and LL successful achievements.

The choice to use GVs, as elsewhere shown $[14,16$, $18,20]$, turned out to be appropriate. GVs functioned as activators of novel working visions, healing fearful and doubtful attitudes, and leading to revisions of emotional and linguistic detachments from the TG and the academic context. GVs also proved to be valid educational tools for affective changes, attitudinal readjustments, and pedagogical developments.

Visualizations helped the students to virtually live their own dream with all of their senses and independently from the teacher. They saw themselves successfully interacting with native speakers of English in their dream land and dream town. They felt the joy of being understood: flawless and fluent in English. They experienced the pleasing sensation that communicating with native speakers of TL offers to those who are learning it, without feeling diminished by personal deficiencies or controlled by evaluators.

Their voices resonate in the following examples and call for revisions in methodological formats and pedagogical approaches:

\section{EN}

While I was imaging, I thought to the trip of my dreams: an airplane was carrying me to London.

I was really excited and I was looking forward to arrive there! [...] I felt happy and nervous at the same time! At the moment of landing the city's lights began to see themselves.

I felt at home and nothing could ruin that wonderful sensation!

The London airport was full of people with the luggages and the tickets ready to use. Suddenly I met an English boy and we immediately began to make friends. [...] The good things was that I could express myself without difficulty and simultaneously I could understand with clarity and semplicity all things that Matthew said of himself.

I didn't believe it! [...]

It's impossible to describe all emotions I felt while I was freely speaking English and I was looking those stupendous places!
I felt different, almost a best person!

I realized that all my efforts in the study were been repayed and all the difficults that I had met seemed only a distant memory!

This dream will always remain inside of me. In bad times I'll remember it and I'll think that at the end it isn't unrealizable.

It's enough a bit of determination and great desire to learn!

\section{2_10_10_EN}

During this $\mathrm{xxx} \mathrm{xxx} \mathrm{xxx}$-imaginery trip I felt very happy and relaxed. The sensation was first strange then ok and then wonderful. In a vortex my mind sees images and scenes I follow the voice but I also go to dream land by myself. [...] My fears were in another land ... not with me

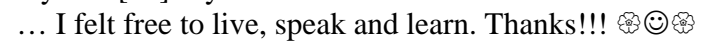

\section{2_06_19_EN}

During the experiment I felt very happy, because I forgot my problems, I just $* x *$ remembered $* x$ happy moments: when I was at $\mathrm{Xxx}$ school and I $\mathrm{xxx}$ joked $\mathrm{Xxx}$ with my xxx schoolmates. $x x x$ xxx I would like to come back to the High School. $x x x x x x$ During the experiment my mind was full and I felt $\mathrm{xxx} \mathrm{xxx}$ the power to follow university lessons and the exams. I like english so much and the experiment was so important to understand better myself and to understand that $\mathrm{xxx} I$ can improve my english. [...]

\section{2_09_87_EN}

[...] Everything was very peaceful [...] so I could think about my trip and my new reality in a XXX-country I had always thought $\mathrm{XXX} \mathrm{XXX} \mathrm{XXX} \mathrm{XXX}$ of for many years now. The suitcase was still empty ... but my mind was full of ideas. They were running like clouds in the wind.

After erasing all my insuccesses and my bad experiences with the language I felt anew, alive, light and ready to $x x x$ *XXgo and continue this lovely adventure $x X X X x x$.

Then the scene changed. I was adult, I was in my office in New York, $X X X X X X X X X X X$ giving orders, answering phones and buying pieces of arts.

Yes, $X X$ this is going to be my future. SUCCESS, MONEY, FREEDOM and ME

Clearly, these texts show that old doubts and fears disappeared and left room for more mature attitudes toward LL. Indeed, visualizations allow for an integration of the rational and emotional worlds as well as for the combination of the valuable results that ELPs and GVs can give to building self-awareness and selfassessment. Brown [4] suggests that when people visualize themselves speaking a new language fluently and interacting with others, then the situation is mentally activated as if they have done that before. This occurs because the nature of stimuli, whether imaginary or perceived as real, does not change the mental state a person experiences. Since our subconscious mind is not capable of distinguishing between reality, thoughts, and images, we experience a mental vision we have as real, and ultimately the vision becomes real [39]. 
The data contained in the EFL P.Æ.C.E. Corpus fully support this analysis. As the above examples well illustrate, mental images can be so vivid and motivating that they make students revise their mental belief-set and manifest desires to commit to studying English in a disciplined, constant way, putting aside incoming negative and demotivating ideas, expressing an empowered motivation, and reactivating or potentiating their sense of personal responsibility. Languageoriented, attitude-geared transformations like these help students become conscious of language matters in general and their sense of being responsible for their success in LL in particular.

\section{Conclusion}

When learning a FL, emotionally bound negative self-representations and self-images may stress students so much that they become demotivated and frustrated to the point where they drop out of FL classes. In extreme cases, they abandon college altogether. Although there seems to be no specific magic formula or wand to transform students with limited competence, low selfesteem, and poor motivation into students with confidence, self-motivation, and willingness to achieve their goals and concretize their visions, the implementation of an affective-geared approach integrated with functional state-changing NLP activities has proven to greatly favor the transformation [4] from ugly ducklings into swans [19].

In spite of their significance in the development of efficacious and long-lasting results, the emotional aspects of LL are still only marginally investigated as if the dichotomy between rational (theories, applications and practices) and emotional (affect-geared investigations) worlds, favored in the last two centuries, should still need to exist. The findings of the present longitudinal study suggest that what students manifest in personality descriptions and self-declarations of intent needs to be taken into serious account as revealing tools for FLT approaches to come. The findings advocate that both rational and emotional aspects of LL integrate and give birth to innovative unified approaches to teaching and learning foreign languages in order to create a more affectively efficient learning modality, with consequent advantages for teachers and students. Are language educators ready for this new transformation?

Indeed, in the light of what has been so far argued, it would be desirable for teacher-training courses to come to consider the power of mental representations in building working visions for the leaders of tomorrow. It is time for new FL teachers to be trained not only in language teaching theories, methodological strategies, and daily classroom techniques but also in the creation and nurturing of affective-oriented learning contexts. Doing that would fulfill the updated integrative needs (as derivable from working with ELPs and GVs) that students desire and want to concretize.

The present article has shown that many students come to university with a clear vision of who they want to be and why. But they also demonstrate a number of added limiting factors (low self-esteem, flickering motivation, poor self-discipline and study skills, unrealistic expectations about how long mastering a FL takes, exaggerated beliefs about their incoming competence level, and many different types of fears) that inhibit or block the concretization of their educational vision. The unobtrusive observations about their emotional states revealed the importance of nurturing visions of success in FLL. GVs may be of help in this: they may allow students, in the privacy of their minds, to revise negative thoughts, fears, years of frustration, and eventually set themselves free to learn without pedagogical burdens.

Clearly, visualizations alone will not suffice. Students will have to work on their passion to make it come true. Feasibly, they will go forward and reach their goals faster and smother than with limiting beliefs. Students are human beings first and learners second. It is this human side that feels, experiences, and grows. In the process of expanding personal universes of knowledge, students mature and get ready for jobs in the multilingual and multicultural world we all live in, ready to become the leaders of tomorrow. Our task, as FL educators, is to make this natural process of epistemological transformation smooth, rich, and enjoyable.

The possibility of creating for them and with them new visions for LL and LT is appealing but needs to be investigated further and then to be emphasized in teacher-training courses. Quantitative analyses, for example, would better measure the results of other researchers. The EFL P.Æ.C.E. Corpus was made electronically available to interested researches with this goal in mind and further investigations in perspective.

\section{References}

[1] Altman, H.B., and C.V. James, (eds.), Foreign Language. Teaching: Meeting Individual Needs, Pergamon, Oxford, 1980.

[2] Arnold, J., (ed.), Affect in Language Learning, Cambridge University Press, Cambridge, 1999.

[3] Bachman, L. F., "Learner-directed assessment in ESL," in G. Ekbatani, and H. Pierson, (eds.), Learner-directed assessment in ESL, Lawrence Erlbaum Associates, Inc., New Jersey, 2000, pp. ix-xii. 
[4] Brown, H.D., Breaking the Language Barrier, Intercultural Press, Yarmouth, ME., 1991.

[5] Brumfit, C.J., and K. Johnson, (eds.), Communicative Approach to Language Teaching, Oxford University Press, Oxford, 1979.

[6] Council of Europe, Common European Framework of Reference for Languages: Learning, teaching, assessment, Cambridge University Press, Cambridge, 2001.

[7] CEFR Global Scale, [Online] Available at http://www.alte.org/ [Accessed July 27 2011].

[8] Dilts, R., Creare Modelli col la PNL, Astrolabio, Milano, 2003.

[9] Dilts, R., and J., DeLozier, Encyclopedia of Systemic Neuro-Linguistic Programming and NLP New Coding. NLP Universty Press, Santa Cruz, CA., 2000.

[10] Harrison, L., (ed.), Learner Independence Worksheets, IATAFEL. Learner Independent Special Interest Group, Kent, U.K., 1997.

[11] Holec, H., Autonomy and Foreign Language Learning, Pergamon, Oxford, 1981, [first published 1979, Strasbourg, Council of Europe).

[12] Jarvis, P., Adult Education and Lifelong Learning, RoutledgeFalmer, New York, 2004.

[13] Johnson, R.K., (ed.), The Second Language Curriculum, Cambridge University Press, Cambridge, 1989.

[14] Landolfi, L., "Emotions and visualizations: where heart and mind intermingle," in A. Shafaei and M. Nejati, (eds.), Annals of language and Learning: Proceedings of the 2009 International Online Language Conference, UniversalPublishers, Boca Raton, FL., USA, 2009, pp. 192-208.

[15] Landolfi, L., "E-motiv-azione,” in F. Dalziel, S. Gesuato, and M.T. Musacchio (eds.) A lifetime of English studies. Essays in honour of Carol Taylor Torsello, Il Poligrafo, (in press) Padova,

[16] Landolfi, L., "Emotività e visualizzazioni in contesti formali di apprendimento linguistico" in VII Congresso AItLA. Aspetti linguistici della comunicazione pubblica ed istituzionale, Guerra Edizioni, Perugia, 2007, pp. 455-486.

[17] Landolfi, L., "Formazione docenti: L'anello mancante," in M. Mezzadri, (ed.), Le lingue dell'educazione in un mondo senza frontiere, Guerra Edizioni, Perugia, 2010, pp. 281-293.

[18] Landolfi, L., The EFL P.Æ.C.E. Corpus. Liguori Editore. Napoli. In press.

[19] Landolfi, L., "Ugly Ducklings or swans? The Magic on NLP in transforming students' perspectives," in M. Pirozzi, (ed.), "Neuroscience and Foreign Language Learning:"A journey in the human brain”, Edizioni Melagrana, S. Felice a Cancello (CE), Italy, 2008, pp. 45-67.

[20] Landolfi, L., "Voice to students," in $7^{\text {th }}$ International Conference on Education, Conference proceedings. Samos, Greece, Volume II, July 7-9, 2011, pp. 164-169.

[21] Levine, S.J., Getting to the Core: Reflections of Teaching and learning, Lighting Source Inc., La Vergne, TN USA, 2005.

[22] Little, D., Learner Autonomy 1: Definitions, Issues and Problems, Authentik, Dublin, 1991.

[23] Littlewood, W.T., Foreign and Second Language Learning: Acquisition, Research and its Implications for the classroom, Cambridge University Press, Cambridge, 1984.

[24] Mariani, L., and P. Tomai, Il Portfolio delle Lingue. Metodologie, proposte, esperienze, Carocci Faber, Roma, 2004.
[25] Moskowitz, G., Caring and Sharing in the Foreign Language Class, Newbury House Publishing, New York, 1978.

[26] Munby, J., Communicative Syllabus Design, Cambridge University Press, Cambridge, 1982.

[27] Nunan, D., The Learner-Centred Curriculum, Cambridge University Press, Cambridge, 1988.

[28] Oller, J.W., (ed.), Methods that Work: Ideas for Literacy and Language Teachers, Heinle \& Heinle, Boston, MA., 1993.

[29] Porcelli, G., Principi di Glottodidattica. Editrice La Scuola, Brescia, Italia, 1994.

[30] Richards, J., 'Language curriculum development' RELC Journal, 15, 1, pp.24-30, 1984.

[31] Richards, J.C., and T.S. Rodgers, Approaches and Methods in Language Teaching, Cambridge University Press, Cambridge, ( ${ }^{\text {nd }}$ Ed.), 2001.

[32] Rivers, W., Teaching Foreign-Language Skills, The University of Chicago Press, Chicago, 1972.

[33] Roby, W.B., "Technology in the service of foreign language teaching: The case of the language laboratory," in D. Jonassen, (ed.), Handbook of Research on Educational Communications and Technology, $2^{\text {nd }}$ ed., 2004, pp.523-541, [Online], Available at http://www.aect.org/edtech/19.pdf. [Accessed July 26 2011].

[34] Scharle, A., and A. Szabo, Learner Autonomy: A guide to developing Learner Responsibility, Cambridge University Press, Cambridge, 2000.

[35] Schumann J. H., The Neurobiology of Affect in Language, Blackwell, Boston, 1997.

[36] Stevick, E.W., Working with Teaching Methods: What's at stake? Oxford University Press, New York, 1998.

[37] Trim, J., "The place of needs analysis in the Council of Europe Language Project,” in Altman, H. B. and C. V. James (eds.), Foreign Language. Teaching: Meeting Individual Needs, Pergamon, Oxford, 1980.

[38] Ur, P., A Course in Language Teaching, Cambridge University Press, Cambridge, 1996.

[39] Webster, R., Creative Visualizations for Beginners. Llewellyn Publications, Woodbury, MI., 2005.

[40] Widdowson, H.G., Teaching Language as Communication, Oxford University Press, Oxford, 1978.

[41] Wilkins, D.A., Notional Syllabuses, Oxford University Press, Oxford, 1976. 